\title{
Induction of Cardiovascular Anaphylaxis and Basic Pharmacological Analysis of Involved Mediators in Pithed Rats
}

\author{
Kwan Ha PARK* \\ Department of Aquatic Life Medicine, College of Ocean Science and Technology, Kunsan National University, \\ Miryong-dong San 68, Kunsan City, Chonbuk, Republic of Korea
}

(Received September 2, 2008; Revised November 2, 2008; Accepted November 6, 2008)

\begin{abstract}
Active cardiovascular anaphylactic response was induced in ovalbumin-sensitized, pithed SpragueDawley and Wistar rats. On intravenous administration of the antigen, ovalbumin, marked tachycardia and pressor responses were immediately elicited. Thereafter, a delayed long-lasting severe hypotensive response was observed. These anaphylactic cardiovascular responses were maximal 2-3 weeks after the sensitization, and the response was slightly diminished 6 weeks after sensitization. The immediate pressor response was blocked by a non-selective serotonin antagonist methysergide at a dose-dependent manner, but not by histamine receptor antagonists mepyramine (pyrilamine) or cimetidine. The delayed hypotension was reduced either by histamine $\mathrm{H}_{1}$ receptor antagonist mepyramine or $\mathrm{H}_{2}$ receptor antagonist cimetidine, both in a dose-dependent manner. The tachycardic response was not influenced by serotonin or histamine receptor antagonists examined in this study. Differently from the cardiovascular responses, there was no observable bronchial contraction in Sprague-Dawley rat trachea in contrast to Wistar rat where the trachea contracted to in vitro antigen challenge. The cardiovascular anaphylactic model seems to be useful for studying cardiovascular events that occur exclusively in peripheral heart-blood vessel systems. The involvement of two major anaphylactic mediators, serotonin and histamine, is partially demonstrated.
\end{abstract}

Keywords: Cardiovascular anaphylaxis, Rat, Serotonin receptor, Histamine receptor

\section{INTRODUCTION}

Anaphylaxis is an acute, life-threatening allergic event caused by many potential triggers (Kelly and Patterson, 1974). Of multiple clinical symptoms of anaphylaxis, the most prominent adverse physiological responses occur in the cardiovascular and pulmonary systems. Patients suffer fainting (syncope) and chest pain distress resulting from dramatic changes in cardiovascular functions in particular due to hypotension (El-Shanawany et al., 2008). The release of several mediators from mast cells and basophils responsible for these clinical symptoms has been proposed (Levi, 1988).

In studying anaphylaxis, various in vivo and in vitro models, mostly employing animals and their tissues, have been introduced (Saito and Nomura, 1989). Pithed animals are devoid of central control because of central ner-

${ }^{*}$ Corresponding author

Tel: +82-63-469-1885, Fax: +82-63-463-9493

E-mail: khpark@kunsan.ac.kr vous system destruction during surgical preparation (Gillespie et al., 1970). This fact provides investigators with the advantage of understanding of cardiovascular responses without the interference of central nervous function. It would be possible to monitor physiological responses in anaphylaxis solely at the peripheral level.

Rats have been recognized as the animal of primary choice for most animal experiments because of easy handling, low cost, and ample background data. Out of several rat strains, Sprague-Dawley is in particular the most widely used one in almost all main pharmacological studies. In contrast, Sprague-Dawley rats have been utilized to a limited extent in allergy-related experiments: the reason for this may be related to the relative instability of reproducible antigen-antibody reactions in this strain. Wistar rats, in contrast, predominantly have been used as the standard strain for this purpose (Church, 1975; Gomes et al., 1994; Kamei et al., 1993; Katayama et al., 1978; Misawa, 1988; Vleeming et al., 1991).

There is no anaphylaxis study conducted in pithed rats despite the above-mentioned advantages in using this 
specific animal model. The objectives of the present study were to characterize anaphylactic cardiovascular responses in rats devoid of central regulation, and to examine the effects of anaphylaxis-alleviating pharmacological antagonists on blood pressure and heart rate responses. It was also explored whether anaphylaxis can be equally induced in the pulmonary system in two strains of rats, Sprague-Dawley and Wistar.

\section{MATERIAL AND METHODS}

\section{Animals}

Male Sprague-Dawley and Wistar rats $(250-300 \mathrm{~g})$ were purchased from Damul Science (Daejon, Korea). They were specific-pathogen free, and were acclimated to a ventilated rodent chamber for a week before the start of experiment. Throughout the experiment, animals were kept at $21 \pm 1^{\circ} \mathrm{C}$ room temperature, $55 \pm 2 \%$ relative humidity. Feed and water were supplied ad libitum.

\section{Anaphylaxis in pithed rats}

Rats were sensitized with turkey egg albumin (ovalbumin, Grade VI, Sigma, dissolved in saline), by injecting 10 $\mathrm{mg} / \mathrm{rat}$, i.p., for two consecutive days. On day 21 (Week 3) following the first sensitization, animals were used to monitor cardiovascular responses on antigen challenge (Sun et al., 1992). The sensitization procedure was successful without adjuvant co-administration. For testing optimal anaphylactic responses, rats were challenged on 7,14 and 42 , instead of 21 days in some rats.

Under light anesthesia with ether, the trachea was cannulated with a stainless tracheal tubing. The rats were then pithed with a copper pithing rod (diameter $2.2 \mathrm{~mm}$ ) through the right orbit pushing down through the spinal column as described by Shiply and Tilden (1947). During this surgical preparation, the brain and spinal column structures were maximally destroyed. Thoracic sympathovagal nerves were sectioned. The right common carotid artery and jugular vein were respectively cannulated with PE-50 polyethylene cannula for cardiovascular measurement and intravenous administration of drugs. Using a rodent respirator (Harvard Apparatus, Holliston, MA, USA), rats were artificially ventilated at 60 strokes $/ \mathrm{min}$ with room air at $1 \mathrm{ml} / 100 \mathrm{~g}$ body weight rate and body temperature was maintained at $37^{\circ} \mathrm{C}$ with a water bath. Blood pressure and heart rate were recorded with a pressure transducer and cardiotachometer and the signals were recorded in a physiography (Polygraph 4006, Letica, Barcelona, Spain).

For anaphylaxis induction, the antigen ovalbumin (5 $\mathrm{mg} / \mathrm{rat}$ ) was administered through the cannula inserted into the jugular vein. When the effects of antihistaminic or anti-serotonergic agent were tested, drug were administered through the jugular vein cannula at 10 min prior to antigen challenge. As only one anaphylactic induction is possible, separate animals were used in each test.

The vital cautions to be taken during surgery were the removal of mucus before starting artificial respiration, and the maintenance of body temperature. Use of ether for anesthesia unavoidably produced mucus production, and the involuntary air inflow by the respirator often led to immediate death due to the loss of necessary swallowing reflex.

\section{Isolated rat trachea}

Some rats, both Sprague-Dawley and Wistar strains, were sacrificed 21 days after sensitization by bleeding under ether anesthesia. The skin and superficial muscles around the ventral cervix were removed to expose trachea. The trachea was dissected out at a length of 4-5 cartilage rings, and longitudinally cut open along the fibrous attachment (Park et al., 2002). The open ring was suspended in a $20-\mathrm{ml}$ organ bath containing $95 \%-\mathrm{O}_{2} / 5 \%$ $\mathrm{CO}_{2}$-saturated Krebs-Henseleit solution ( $\mathrm{pH}$ 7.4). Cell pins were used to connected to an isometric transducer (Hugo-Sachs, West Germany) placed above the tissue and a fixing stirrup at the bottom of the bath. The tissue was washed repeatedly with fresh Krebs-Henseleit solution to obtain a stable resting tension of approximately 0.1 $\mathrm{g}$ at $37^{\circ} \mathrm{C}$. Anaphylactic response was induced by adding ovalbumin $1 \mathrm{mg}$ directly to the bath.

\section{Drugs}

Drugs were purchased from the following sources and dissolved in physiological saline: ovalbumin (turkey egg albumin, Sigma, St. Louis, MO, USA), pyrilamine maleate (Sigma, termed as mepyramine), methysergide maleate (Sigma, termed as methysergide), and cimetidine (Research Biochemicals International, Natick, MA, USA)

\section{Statistics}

All data were expressed as mean \pm S.E.M. When oneway ANOVA analysis led to statistical significance $(p<0.05)$, Duncan's multiple range test was performed to judge significance among groups. When $p$-values were $<0.05$, the two means were considered significantly different.

\section{RESULTS}

\section{Cardiovascular anaphylaxis in pithed rats}


(A) Sprague-Dawley

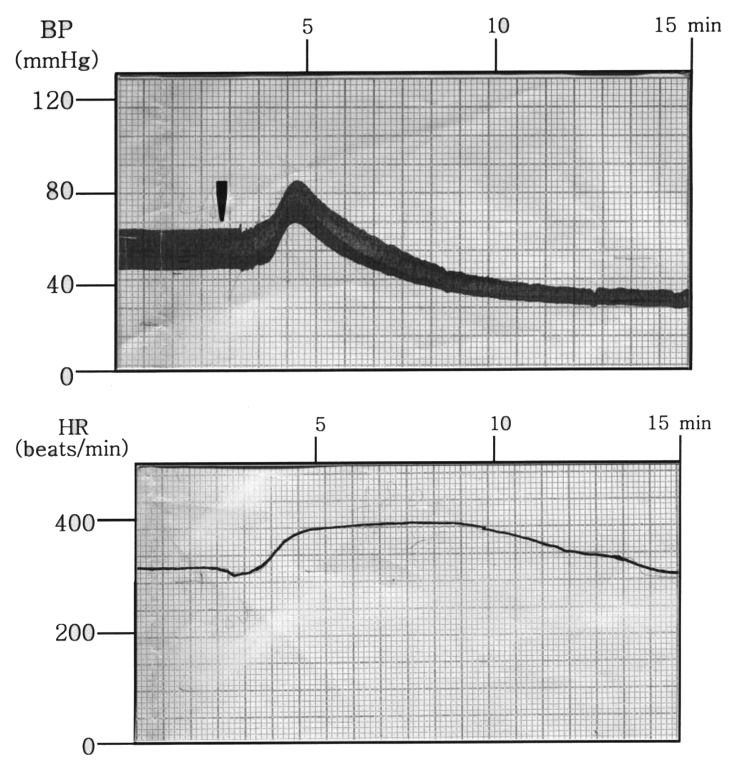

(B) Wistar
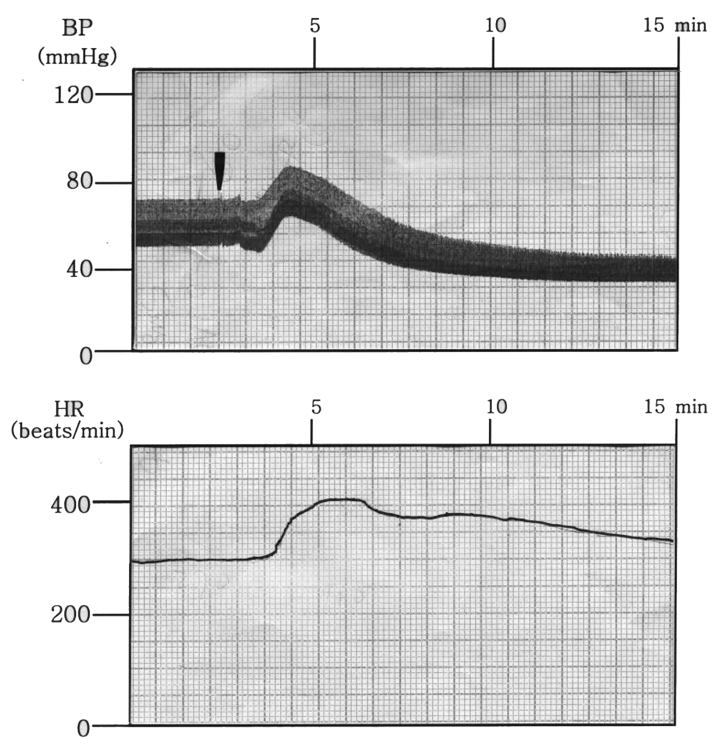

Fig. 1. Representative tracings of blood pressure and heart rate responses in anaphylaxis-induced rats

The bar indicator denotes challenging ovalbumin injection. Rats were sensitized with turkey albumin $(10 \mathrm{mg} / \mathrm{rat}, 2$ doses, ip) and used to monitor cardiovascular responses on antigen challenge (5 mg/rat, iv) 3 weeks later.

The induction of anaphylaxis was performed at 3 weeks after the final ovalbumin sensitization as the standard tests. Anaphylactic responses to ovalbumin was elicited at 30 - $50 \mathrm{sec}$ after the intravenous ovalbumin injection. Typical tracings from both Sprague-Dawley and Wistar rats are shown in Fig. 1. There was no qualitative and quantitative differences between the two strains.

There was an immediate pressor response usually peaking at 1-2 min, which was then followed by a gradual, long-lasting drop in blood pressure that stabilized in about $10 \mathrm{~min}$. Occasionally, a weak transient depressor response preceded the pressor rise.

In heart rate, there was a marked tachycardia accompanying the pressor response, but lasted over 5 min in most animals. The tachycardia attained its maximal level at about 2 min after the challenge. Significant number of animals (12 out of 28 control rats challenged) died in about $20 \mathrm{~min}$ after challenge. In these fatal animals, arrhythmia appeared before the death. The long-lasting hypotensive responses did not recover to its pre-chal-

(A) Sprague-Dawley

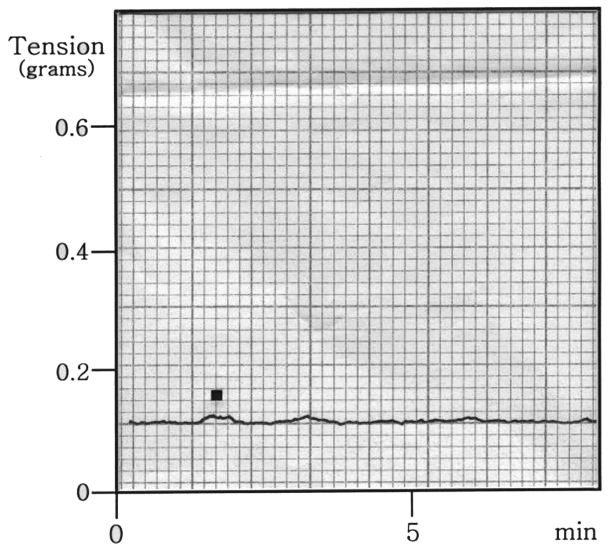

(B) Wistar

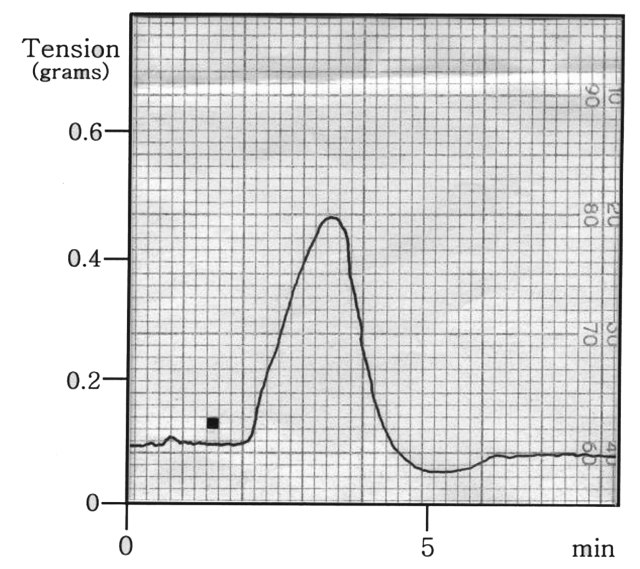

Fig. 2. Representative tracheal responses of sensitized Sprague-Dawley and Wistar rats

The square indicator denotes challenging ovalbumin addition. Rats were sensitized with turkey albumin (10 mg/rat, ip) and used to monitor in vitro tracheal responses on antigen challenge ( $1 \mathrm{mg} / \mathrm{bath}) 3$ weeks later. 
lenge level. When the rat was re-challenged with antigen at about 20 min after the initial one, there was no additional cardiovascular response ( $n=2$, data not shown) indicating that the observed cardiovascular response is attributable to specific immunological reactions.

\section{Tracheal responses in sensitized Sprague-Dawley and Wistar rats}

Fig. 2 shows isolated tracheal responses in two different strains, Sprague-Dawley and Wistar rats, following antigen challenge performed in an organ bath. There was a clear difference in bronchial anaphylaxis between the strains: while Wistar rat trachea contracted with an immediate contraction to antigen challenge $(0.36 \pm 0.30 \mathrm{~g}$ contraction, $n=5)$, that of Sprague-Dawley was completely non-responsive.

Difference in anaphylaxis intensity challenged at different time after immunization in Sprague-Dawley rats

Fig. 3 illustrates cardiovascular responses appeared when challenging antigen was administered at 1, 2, 3 and 6 weeks following sensitization in Sprague-Dawley rats. There was no response after 1 week post immunization; it was evident and maximal after 2 and 3 weeks; the response diminished significantly 6 weeks post sensitization.

\section{Effects of histamine and serotonin receptor antago- nists on cardiovascular anaphylaxis in Sprague- Dawley rats}

Involvement of two well-known anaphylactic mediators, histamine and serotonin was examined in SpragueDawley rats (Fig. 4). The immediate pressor response was significantly diminished by pre-treatment with a nonselective serotonin antagonist, methysergide. This pressor response was influenced neither by histamine $\mathrm{H}_{1}$ receptor antagonist mepyramine nor by histamine $\mathrm{H}_{2}$ antagonist cimetidine. The delayed, long-lasting hypotensive reaction was diminished by mepyramine in a dosedependent manner. This hypotension was also attenuated by cimetidine. When the rat was co-treated with mepyramine and cimetidine both at medium doses, the hypotension was almost completely abolished. As mentioned above, there was a marked increase in heart rate on anaphylaxis induction. The tachycardia was not influenced by histamine or serotonin receptor antagonists examined.

\section{DISCUSSION}

An active systemic anaphylaxis was evoked in pithed

\section{(A) Pressor response}

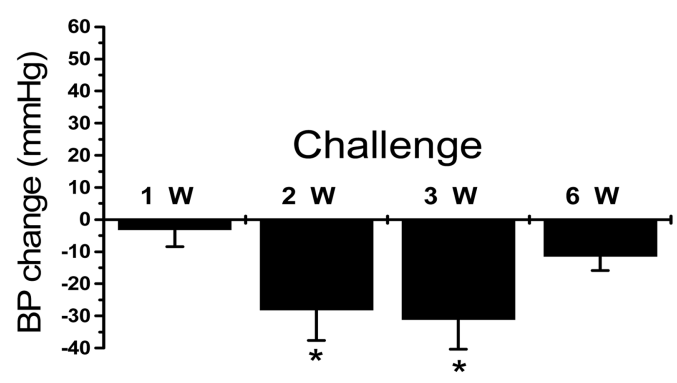

(B) Depressor response

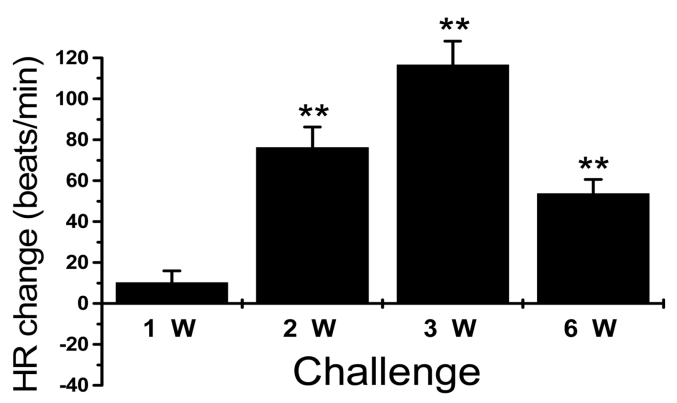

(C) Tachycardia



Fig. 3. Cardiovascular anaphylaxis responses in SpragueDawley rats induced at different time points following sensitization

Rats were sensitized with turkey albumin $(10 \mathrm{mg} / \mathrm{rat}, 2$ doses, ip) and used to monitor cardiovascular responses on antigen challenge $(5 \mathrm{mg} / \mathrm{rat}$, iv) after $1,2,3$ or 6 weeks.

Significant difference from week 1 at $p<0.05\left(^{*}\right)$ and $p<0.01$ $\left(^{* *}\right) . N=7$

rats and analysis on the involvement of two major anaphylactic mediators involved was examined using pharmacological antagonists. Pithed rat model is unique in that central mechanism on cardiovascular control is totally abolished. This model thus had been developed earlier to assess blood pressure responses occurring exclusively in the peripheral organs (Shipley and Tilden, 1947). On challenge to antigen in ovalbumin-sensitized 


\section{Methysergide}
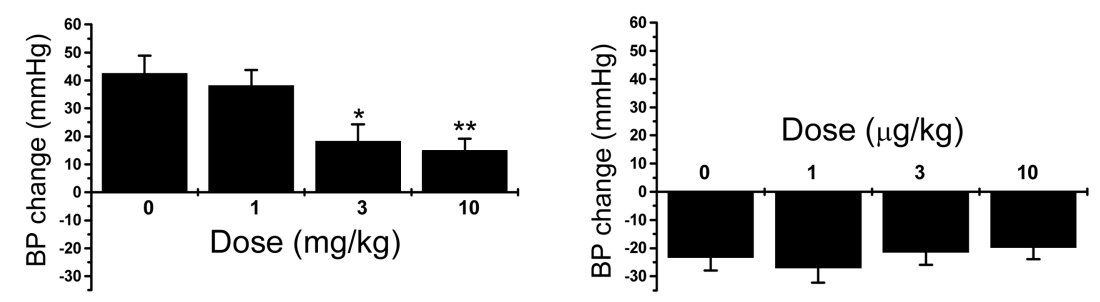

\section{Mepyramine}
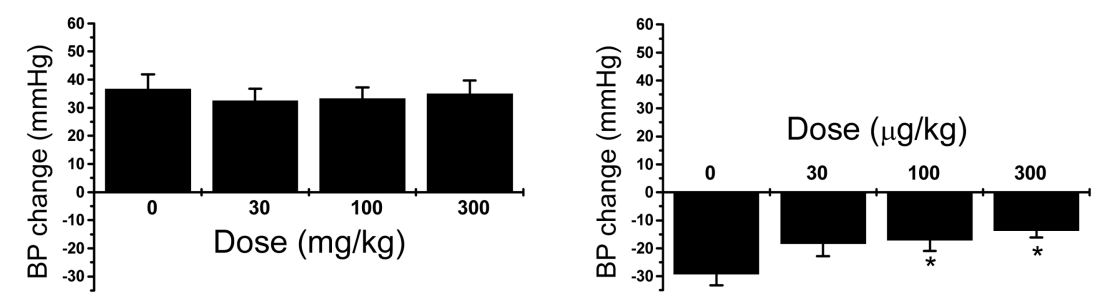

\section{Cimetidine}
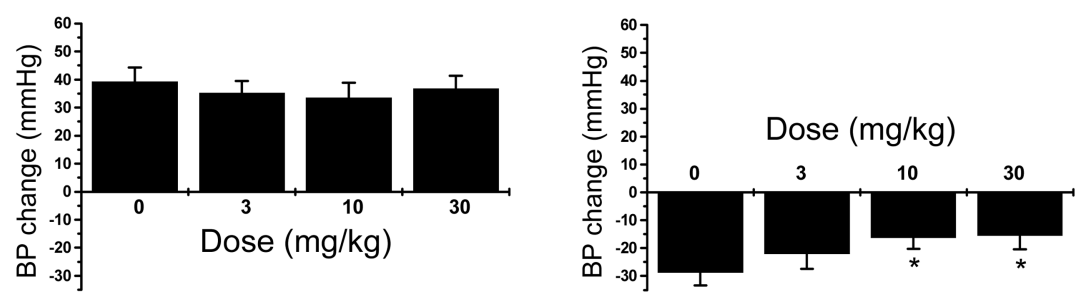

\section{Mepyramine + cimetidine}

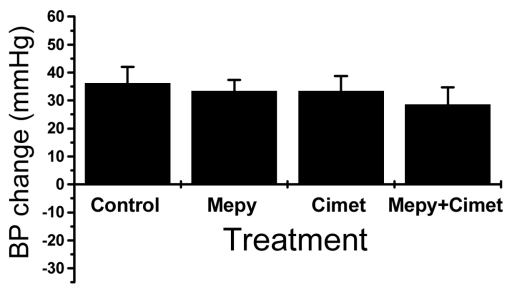

Pressor response (A)

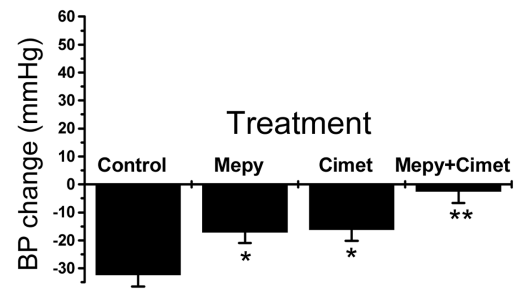

Depressor response (B)

Fig. 4. Effects of serotonin and histamine receptor antagonists in Sprague-Dawley rats against cardiovascular anaphylaxis Rats were sensitized with turkey albumin (10 mg/rat, 2 doses, ip) and used to monitor cardiovascular responses on antigen challenge (5 mg/rat, iv) 3 weeks later. Graphs on left and right columns respectively illustrate pressor and depressor responses. In rats co-administered with mepyramine and cimetidine, doses were $100 \mu \mathrm{g} / \mathrm{kg}$ and $10 \mathrm{mg} / \mathrm{kg}$, respectirely.

Significant difference from control at $p<0.05\left(^{*}\right)$ and $p<0.01\left(^{* *}\right) . N=7$

rats, there were an immediate pressor and a delayed depressor responses thereafter. In the heart rate a longlasting tachycardia was observed. This complex cardio- vascular response was equally inducible in SpragueDawley and Wistar rats. The anaphylactic response was maximally inducible 2 - 3 weeks following sensitization, 
and seemed to be maintained several weeks thereafter allowing sufficient room for study using this model.

It was demonstrated in sensitized intact rats or mice under anesthesia that on antigen challenge only hypotension and tachycardia were observable (Lei et al. 1992; Sun et al., 1992). They could not observe pressor responses, and this study is the first report of an immediate pressor response in a systemic anaphylaxis in a rodent. The reason for this difference is not known at the present. However, one can speculate that other investigators might have failed to observe pressor responses because of higher basal blood pressure levels in intact animals with central nervous system in operation. The basal mean blood pressure ranged $50-60 \mathrm{~mm} \mathrm{Hg}$ in the pithed rats, whereas the level in intact status is known to be about $100-130 \mathrm{mmHg}$. Although Sprague-Dawley is the most frequently utilized rat strain for a variety of pharmacological experiments, it has been limitedly used in the area of immuo-pharmacology. In an earlier study by Bartlet (1963) it was proposed that rat heart does not contain histamine receptors and therefore there was no anaphylactic response in the heart of this species (Lecomte and Cession-Fossion, 1970). In accordance with such reports, the chronotropic action found in pithed status was not influenced by two histamine receptor antagonists, mepyramine or cimetidine.

Two histamine receptor antagonists were tested to examine the involvement of each receptor subtype, $\mathrm{H}_{1}$ and $\mathrm{H}_{2}$ in view of the fact that histamine is the major mediator of active systemic anaphylaxis (Levi, 1988; Sun et al., 1992). $\mathrm{H}_{1}$-receptor antagonist mepyramine significantly reduced the depressor response indicating that the reaction in anaphylaxis may be related to vasodilatory effect of released histamine via an activation of $\mathrm{H}_{1}$-receptor present on resistance blood vessels. For this hypotension, histamine seems to stimulate cimetidine-blockable $\mathrm{H}_{2}$ receptors as well. Normally, the vaso-depressor response induced by histamine injection in rats can be attributable to the stimulation not only of histamine $\mathrm{H}_{1}$ but also $\mathrm{H}_{2}$ receptors present in blood vessels (Malinnowska and Schlicker, 1993). Serotonin is known to be present in a large amount in mast cells and released in response to anaphylactic stimulus (Lima, 1967). This autacoid seems to be involved in the pressor response of rat anaphylaxis. In fact serotonin can cause vasoconstriction in rat resistance vessels (Frodi et al., 2008).

From the current observation, it is clear that mediator(s) which cause hypertension must have been produced in intact animal anaphylaxis, but their physiological effects might have been masked by marked hypotension that ensues. Furthermore, baroreflex may attenuate increased pressor through the participation of central nervous system in intact animals. These ponits need clarification, however. In the present pithed rats, however, the pressor response was revealed probably because the baroreflex loop was excluded by pithing. Thus the present result indirectly demonstrates the involvement of pressor mediator(s) released during anaphylaxis in rats. The pressor activity can not be a secondary reaction to the increased heart rate because the tachycardia lasted longer than the pressor responses.

It is interesting that although the anaphylactic response was evident in cardiovascular system, it was completely absent in the trachea of the same Sprague-Dawley rat. Anaphylaxis-producing homologous antibody ( $\mathrm{lgE}$ ) can be produced in the Sprague-Dawley rats but this strain maybe cannot elicit bronchial constriction because of the lack of histamine receptor in the trachea of this strain. When Wistar rats were passively immunized with Sprague-Dawley-produced antibody, bronchial constriction occurred (Farmer et al., 1975). The current result indicates that Sprague-Dawley rats can be a model to study cardiovascular anaphylaxis without the involvement of bronchial system.

This pithed rat model may be useful in assessing the effects of unknown drug candidates, especially those of anti-anaphylactic agents. In addition to the advantage of excluding central components of response, the blood pressure in pithed rats is extremely stable throughout the experiment enabling measurement of minute changes. In contrast, blood pressure level will fluctuate in conscious or anesthetized condition, and intermittent additional anesthetic is usually required in anesthetized animal experiments. Only ether was used for surgical anesthesia induction during pithing and no further anesthetic was needed.

In summary, it was demonstrated that pithed rat is a useful systemic anaphylaxis model in which the involvement of central control can be excluded. Most of the anaphylactic blood pressure changes in pithed rats seem to be derived from released histamine and serotonin from mast cells.

\section{ACKNOWLEDGMENT}

The authors are grateful to the Fisheries Science Institute of Kunsan National University for equipments and funding in the program year of 2008. 


\section{REFERENCES}

Bartlett, L. A. (1963). The action of histamine on the isolated heart. Brit. J. Pharmacol. Chemother. 21, 450-461.

Church, M. K. (1975). Response of rat lung to humoral mediators of anaphylaxis and its modification by drugs and sensitization. Br. J. Pharmacol. 55, 423-430.

El-Shanawany T., Williams P. E. and Jolles S. (2008). Clinical immunology review series: an approach to the patient with anaphylaxis. Clin. Exp. Immunol. 153, 1-9.

Farmer J. B., Richards, I. M. Sheard, P. and Woods A. M. (1975). Mediators of passive lung anaphylaxis in the rat. Brit. J. Pharmacol. 55, 57-64.

Frodi, G., Montopoli, M., Zanetti, M, Dorigo, P. and Caparrotta, L. (2008). 5- $\mathrm{HT}_{1 \mathrm{~B}}$ receptor subtype and aging rat blood vessels. Pharmacology 81, 70-78.

Gillespie, J. S., MaClaren, A. and Pollock, D. (1970). A method of stimulating different segments of the autonomic outflow from the spinal column to various organs in the pithed cat and rat. Br. J. Pharmacol. 40, 257-267.

Gomes, J. C., Di Stasi, L. C., Sgarbosa, F. and Barata, L. E. S. (1994). Pharmacological evaluation of the inhibitory effect of extracts from Anchietia salutaris on the histamine release induced in the rat and the guinea pig. Int. Arch. Allergy Immunol. 103, 188-193.

Grave, L. M., Robertson, D. A., Levi, R., Beaker, C. G., Weksler, B. B., and Gay, W. A. (1996). IgE-mediated hypersensitivity in human heart tissue: histamine release and functional changes. J. Allergy Clin. Immunol. 77, 709-714.

Kamei, C., Sugimoto, Y., Nakamura, S. and Zhong, C. (1995). Effect of (Z)-11-[3-(dimethylamino)propyridene]-6,11-dihydrodibenz[b,e]oxepin-2-acetic acid hydrochloride on experimental allergic conjunctivitis and rhinitis in rats and guinea pigs. Arzneim.-Forsch. 45, 1105-1108.

Katayama, S., Shionoya, H. and Ohtake, S. (1978). A new method for extraction of extravasated dye in the skin and the influence of fasting stress on passive cutaneous anaphylaxis in guinea pigs and rats. Microbiol. Immunol. 22, 89-101.

Kelly, J. F. and Patterson, R. (1974). Anaphylaxis: course, mechanisms and treatment. JAMA 227, 1431-1436.

Lecomte, J. and Cession-Fossion, A. (1970). Absence de reactions, anaphylactiques localisées au mycarde du rat. C. R. Soc. Biol. (Paris) 164, 1420-1422.

Lei, H. Y., Chen, H. I., Chan, S. H., Lei., S. S., Lim, S. B. and Wing, L. Y. (1992). Antigen-specific tachycardia and hypertension in rodents. Clin. Exp. Allergy 22. 767-773.

Levi, R. (1988). Cardiac anaphylaxis: models, mediators, mechanisms, and clinical considerations. In: Human Inflammatory Disease, Cliniacl Immunology Vol. 1, (G, Marone, L. M Lichtenstein, M. Condorelli and A. S. Fauci Eds.), pp Decker, Toronto, Canada.

Lima, A. O. (1967). Pharmacologically active substances released during anaphylactic shock in the mouse. Int. Arch. Allergy 32, 46-54.

Malinnowska, B. and Schlicker, E. (1993). Identification of vascular endothelial $\mathrm{H}_{1}, \mathrm{H}_{2}$ and cardiac presynaptic $\mathrm{H}_{3}$ receptors in the pithed rats. Naunyn-Schmiedeberg's Arch. Pharmacol. 343, 55-60.

Misawa, M. (1988). A new rhinitis model using chemical mediators in rats. Jpn. J. Pharmacol. 48, 145-22.

Park, K. H., Park, J., Koh, D., and Lim, Y. (2002). Effect of sakosaponin-A, a terpenoid glycoside, isolated from Bulpreum falcatum on experimental allergic asthma. Phytother. Res. 16, 359-363.

Shipley, R. E. and Tilden, J. H. (1947). A pithed rat preparation suitable for assaying pressor substances. Proc. Soc. Exp. Biol. Med. 64, 453-455.

Weil, M. H., Tang, W., Gazmuri, R. J., Bisera, J., Greenberg, S. R. and Kim, Y. B. (1992). Cardiac anaphylaxis in the Sprague-Dawley rats. J. Lab. Clin. Med. 120, 589-596.

Saito, H. and Nomura, Y. (1989). Screening methods for drug evaluation III, In: Pharmaceutical Research and Development, Vol. 9, eds. by (I. Suzuki, Ed.), pp Hirokawa Publishing Co., Tokyo, Japan.

Vleeming, W., Van Rooij, H. H., Wemer, J. and Porsius, A. J. (1991). Characterization and modulation of antigen-induced effects in isolated rat heart. J. Cardiovasc. Pharmacol. 18, 556-565. 